\title{
Sex is a potent modifier of the cardiovascular system
}

\author{
Leslie A. Leinwand \\ Department of Molecular, Cellular, and Developmental Biology, University of Colorado, Boulder, Colorado, USA \\ J. Clin. Invest. 112:302-307 (2003). doi:10.1172/JCI200319429.
}

Despite the growing number of reports in the literature identifying sex-related differences in cardiac function in both rodents and humans, the underlying mechanisms have yet to be determined. Here, variables of experimental studies such as diet, animal model utilized, and age, in addition to sex hormones and other factors that may play a role in sex-related variations in cardiac responses to various pathophysiological conditions are discussed, suggesting that current approaches used in the study of cardiac disease require reevaluation.

There are numerous health problems that are affected by gender. Women are more susceptible than men to depression, osteoporosis, asthma, lung cancer due to smoking, and autoimmune disease (1). Gender effects in disease are complex, however, as exemplified by the observation that while the incidence of melanoma is slightly higher among women than men, mortality from melanoma is higher in men. Not all medical problems show gender dimorphism. For example, males do not differ from females in terms of their responses to infection (1). When it comes to heart disease, generally, of those individuals diagnosed with heart disease, women fare much better than men. Little is known about the basis for this difference in cardiovascular disease. Much focus has been placed on the potential cardioprotective role of estrogen. However, the recent finding that estrogen replacement in postmenopausal women actually increased heart disease has challenged this view (2).

Deriving a coherent view of potential players in sexdependent differences in the heart requires analysis of both the clinical literature and the literature on sex-dependent differences in the cardiovascular system of laboratory animals. There is a major limiting factor in comparing rodent laboratory studies: the

Address correspondence to: Leslie A. Leinwand, Department of Molecular, Cellular, and Developmental Biology, 347 UCB, University of Colorado, Boulder, Colorado 80309, USA. Phone: (303) 492-7606; Fax: (303) 492-8907;

E-mail: Leslie.Leinwand@colorado.edu.

Conflict of interest: The author has declared that no conflict of interest exists.

Nonstandard abbreviations used: hypertrophic cardiomyopathy (HCM); alcohol dehydrogenase (ADH); myosin heavy chain $(\alpha-\mathrm{MyHC})$; estrogen receptor (ER). vast majority have been carried out on males only. However, this limitation appears to be changing. In the past year, a number of studies have appeared in which both males and females have been analyzed. An article in a recent issue of the JCI by O'Connell et al. (3) provided a glimpse into what promises to be a new way of thinking about genetic sex. In this report, the authors found that the $\alpha_{1}$-adrenergic receptors are critical in determining heart size and the ability of the heart to respond to both pathologic and physiologic stimuli, but only in male animals. Intriguingly, this sex-related difference did not disappear following ovariectomy of females. This article will discuss the fact that sex is an extremely potent modifier of the myocardium and will identify which pathways have been implicated in some of these differences. I hope it will become clear that future research should focus on the mechanisms by which both sex and diet can modify cardiovascular phenotypes.

\section{Sex-related differences in normal male and female hearts in human cardiac disease}

What are the sexually dimorphic cardiovascular differences to which I refer? Before puberty, there are no statistically significant sex-related differences in heart size (4). After puberty, absolute heart mass is greater in men than in women by about $15-30 \%$ (5). Both males and females start out with the same number of cardiac myocytes and the size of their myocytes is initially the same. Therefore, it appears that male myocytes undergo a greater degree of hypertrophy during normal postnatal growth than their female counterparts. In terms of normal function, echocardiography has demonstrated better diastolic function in young women compared to age-matched men, and with aging, men have a decrease in systolic function that is not observed in women (6).

In the most common forms of cardiovascular disease, premenopausal women show a much better prognosis than men. Women show supranormal contractility with increased wall thickness compared to men with similar degrees of aortic stenosis, hypertension, aging, and hypertrophic cardiomyopathy (HCM). Men have poor contractility, chamber dilation, and wall thinning (7-14). Is the more favorable prognosis for females due to the cardioprotective 
properties of estrogen? It is probably not that simple. I say this because of the now famous study that showed that hormone replacement therapy increased cardiovascular events in postmenopausal women (2, 15 ). Further, it is not always the case that women fare better than men in cardiovascular disease. In cases of idiopathic dilated cardiomyopathy, females have a significantly poorer prognosis than males (16). Women are also more sensitive to alcohol-induced cardiac disease (17). In addition, the sex-related differences reverse with age when examining mortality due to cardiovascular disease. More males (39\%) than females die from heart disease between the ages of 45 and 64 . However, after age 65 the death rate due to heart disease in women exceeds that in men by $22 \%$ (18). The combination of these sex-related differences observed in the progression of cardiovascular disease and the increase in mortality in postmenopausal women at the very least deserves more research. Currently, due to the limitations of human studies, the cellular and molecular mechanisms of these differences have yet to be characterized. Therefore, the questions remain: what is the basis for the better prognosis for premenopausal females in heart failure, aortic stenosis, hypertension, and HCM; and, what is the mechanism whereby postmenopausal women have increased mortality compared to their male counterparts?

\section{Rodent studies on sex-related differences in the cardiovascular system}

What can we learn from animal studies about sexrelated differences in heart disease? The literature regarding studies in animals falls into two general categories: (i) studies that deliberately address sex-related differences in the cardiovascular system; and (ii) studies in which the inactivation or manipulation of genes has resulted in the discovery of a sexually dimorphic phenotype. Most of the studies in the first category have involved subjecting wild-type rodents of both sexes to some pathologic or physiologic stimulus and observing how the heart responds (Table 1). These studies have generally been consistent with observations in clinical populations. Studies in the second cat- egory are beginning to provide the groundwork for understanding the basis for sex-related differences noted in the first category (Table 2). However, when we examine the animal model literature, there are two important things to note: Firstly, the majority of the literature is devoted to the study of male animals. Most of the basis for this (although not explicitly stated) is that female animals would need to be studied only at a fixed point in the estrous cycle and this would be impractical. A systematic analysis is warranted in order to analyze the cardiac responsiveness of male and female mice to a variety of stimuli and investigate how diet might modify cardiovascular phenotypes (see Phytoestrogens and heart disease).

On the surface however, rodent studies do not always appear to be consistent. It is important to ask whether the inconsistencies are telling us something meaningful. If the experimental rodent literature is examined closely, some of the inconsistencies can be explained because the studies themselves are not comparable. For example, different results have been obtained in comparing contractile performance in male and female rats. One study in papillary muscles from 6-month old rats found that males had significantly slower rates of contraction and relaxation than females (19). A similar study using the isolated working heart preparation revealed increased cardiac output in males (20). A third study using younger papillary muscles found no difference between the sexes until animals were 6 months of age (21). These alleged inconsistencies suggest that it is not possible to compare apples and oranges. It seems clear that the following parameters need to be assessed when trying to compare one study to another: (i) what are the ages of the animals; (ii) what species and what strain were used in the studies; and (iii) how, in the case of function, were the measurements made? For example, is it possible to freely compare cardiac function as assessed by echocardiography with that assessed in an isolated working heart preparation?

In the case of genetically manipulated rodents, most studies have been done in mice, narrowing one of these variables - species. Strain is still an issue, but

\section{Table 1}

Summary of differences observed in cardiovascular function between males and females

\begin{tabular}{|c|c|c|c|c|}
\hline \multirow{2}{*}{$\begin{array}{l}\text { Cardiovascular component } \\
\text { or characteristic }\end{array}$} & \multirow[t]{2}{*}{ Model system } & \multicolumn{2}{|c|}{ Observed effect } & \multirow[t]{2}{*}{ Reference } \\
\hline & & Males & Females & \\
\hline \multirow[t]{2}{*}{ Aortic constriction } & Rat & $\downarrow$ Systolic function & $\uparrow$ Concentric remodeling & $(51)$ \\
\hline & & $\uparrow$ Diastolic pressure & & \\
\hline \multirow[t]{2}{*}{ Hypertension } & Rat & Left ventricular chamber $\uparrow$ & Left ventricular chamber significantly $\uparrow$ & $(52)$ \\
\hline & & $\downarrow$ Fractional shortening & & $(53)$ \\
\hline \multirow[t]{2}{*}{ Angiotensin-converting enzyme } & Mouse & $\uparrow$ Relative to females & $\downarrow$ Relative to males & $(54)$ \\
\hline & & Orchiectomy $\downarrow$ ACE & Ovariectomy $\uparrow \mathrm{ACE}$ & \\
\hline$\alpha-\mathrm{MyHC}$ & Human & $\uparrow \alpha-\mathrm{MyHC}$ in left ventricle & $\downarrow \alpha-\mathrm{MyHC}$ in left ventricle, relative to males & $(55)$ \\
\hline \multirow[t]{2}{*}{$\mathrm{K}^{+}$current } & Mouse & $\uparrow$ Relative to females & $\downarrow$ Relative to males & $(56)$ \\
\hline & & $\downarrow$ Kv1.5 channel & $\uparrow$ Action potential & \\
\hline Repolarization reserves & Mouse & $\uparrow$ Relative to females & $\downarrow$ Relative to males & (57) \\
\hline
\end{tabular}


Table 2

Summary of male- and female-related differences in genetically manipulated mice

\begin{tabular}{|c|c|c|c|}
\hline \multicolumn{3}{|l|}{ Cardiovascular component } & \multirow[t]{2}{*}{ Reference } \\
\hline or characteristic & Males & Females & \\
\hline$\alpha_{1 A}$ and $\alpha_{1 \beta}$-adrenergic receptor nul & $\begin{array}{c}\text { Small heart; } \\
\text { } \text { exercise performance }\end{array}$ & $\begin{array}{l}\downarrow \text { Aortic restriction response; } \\
\text { heart normal following ovariectomy }\end{array}$ & (3) \\
\hline Constitutively active Akt & $\begin{array}{l}\text { Heart size } \uparrow \text { compared } \\
\text { to wild type }\end{array}$ & $\begin{array}{l}\text { Heart size } \uparrow \text { compared to wild type; } \\
\text { heart size } \uparrow \text { compared to transgenic males }\end{array}$ & $(44)$ \\
\hline Mutant $\alpha-\mathrm{MyHC}$ & $\begin{array}{l}\text { Cardiac chamber dilation; } \\
\text { heart failure }\end{array}$ & Hypertrophy; preserved function & $(58)$ \\
\hline $\begin{array}{l}\text { Mutant cardiac troponin T } \\
\text { (R92Q) }\end{array}$ & Heart size $\downarrow$ compared to wild type & $\begin{array}{l}\text { No change in heart size when } \\
\text { compared to wild type un }\end{array}$ & $\begin{array}{l}\text { (59) (L. Leinwand, } \\
\text { npublished observations }\end{array}$ \\
\hline $\begin{array}{l}\text { Superinhibition of } \\
\text { phospholamban }\end{array}$ & $\begin{array}{l}\text { Progress to dilated cardiomyopathy } \\
\text { at } 6 \text { months of age }\end{array}$ & Hypertrophy; normal cardiac function & $(60)$ \\
\hline Phospholamban overexpression & $\begin{array}{l}\text { Hypertrophy; mortality: } \\
15 \text { months of age }\end{array}$ & $\begin{array}{l}\text { Delayed hypertrophy; mortality: } 22 \text { months } \\
\text { of age despite similar dysfunction in males }\end{array}$ & $(61)$ \\
\hline ADH overexpression & No phenotype & $\begin{array}{l}\text { Myocytes more sensitive to ethanol; } \\
\text { depression of contractions }\end{array}$ & $(62)$ \\
\hline TNF- $\alpha$ overexpression & $\begin{array}{l}\text { Cardiac chamber dilation; } \\
\mathrm{Ca}^{2+} \text { handling is low }\end{array}$ & Hypertrophy; normal $\mathrm{Ca}^{2+}$ & $(63)$ \\
\hline $\begin{array}{l}\text { Lipoprotein lipase I } \\
\text { overexpression/PPAR-null }\end{array}$ & Die at 4 months of age & Live & $(64)$ \\
\hline Relaxin null & Cardiomyopathy & No altered phenotype & $(65)$ \\
\hline $\begin{array}{l}\beta_{2} \text {-adrenergic receptor } \\
\text { overexpression }\end{array}$ & $\begin{array}{c}\uparrow \text { Contractility; } \\
\uparrow \text { ischemia reperfusion injury }\end{array}$ & $\uparrow$ Contractility; normal response to injury & $(66)$ \\
\hline
\end{tabular}

most investigators now backcross their strains onto the C57B1/6 background. The age of the animals is still a major issue for several reasons. Phenotypes of genetically manipulated mice have been shown to vary over time (as mentioned above with wild-type rats). One striking example describes mice overexpressing the $\beta_{2}$-adrenergic receptor $\left(\beta_{2} A R\right)$. At $2-4$ months of age, male $\beta_{2}$ AR mice exhibited enhanced cardiac contractility. Between 8 and 12 months of age the mice developed severe fibrosis and contractile dysfunction (22). A second, and perhaps more important, issue in correlating rodent and human studies, has to do with extrapolating the time frame of rodent studies to humans. Many of the sex-related differences seen in humans do not emerge until well into adulthood, which in a mouse is roughly equivalent to at least 10-12 months of age. When reviewing the literature, it becomes apparent that many studies have been conducted on rats and mice of 4-6 months of age, so conclusions of a lack of sex-related differences in cardiac phenotypes may be premature. That said, now that more studies are including animals of both sexes, it is clear that sex plays a major role in cardiovascular function in rodents. Figure 1 shows a number of pathways implicated in these sex-related differences. As is obvious from the summary of recent studies that have documented sex-related differences in cardiovascular function of genetically manipulated animals (Table 2), in general, females have blunted cardiac responses compared to their male counterparts (or no response in some cases) following manipulation of a number of genes. They also have blunted responses to the inactivation of certain genes. The cardiovascular phenotype observed in females is also blunted or normal in cases of overexpression/activation or expression of a mutation. An augmented response in females has been reported in the case of constitutive activation of Akt, and a worse outcome for females was noted in mice overexpressing alcohol dehydrogenase (ADH).

\section{Sex hormones}

Although the role of estrogen in providing cardioprotection is no longer so clear, this is not to say that sex hormones do not have an effect on the cardiovascular system. Functional estrogen receptors (ERs) $(\alpha$ and $\beta$ ) have been demonstrated in ventricular myocardium of both males and females (23-25). Both receptors have a similar affinity for $17 \beta$-estradiol. Estrogen binding has genomic effects as ERs are ligand-activated transcription factors and can activate transcription of a number of genes whose promoter regions contain tandem estrogen response elements (AGGTCANNNTGACCT)(26). Estrogen also has nongenomic effects. Estrogen has been shown to rapidly decrease calcium current through the L-type $\mathrm{Ca}^{2+}$ channel in isolated cardiac myocytes (27). The effect of estrogen on $\mathrm{Ca}^{2+}$ could be an important regulatory mechanism in cardiac muscle given the central role of intracellular $\mathrm{Ca}^{2+}$ in sarcomere function. Androgen receptors have also been demonstrated in the myocardium of multiple species, including mice (28). In addition, testosterone has been observed to transcriptionally regulate cardiac gene expression $(29,30)$. Gonadectomy is a well-established method to evaluate sex hormone effects on end-organ physiology in animals (31-35) and has been used to evaluate changes in cardiac myosin heavy chain (MyHC) isoform expression (3, 33-35). In gonadectomized rats 
subjected to swimming or renovascular hypertension, gender-appropriate hormone replacement has been shown to provide a beneficial effect on myosin isoform expression, which is considered a marker for pathologic versus physiologic hypertrophy (32). In the recent article by O'Connell et al. (3) as described above, a very interesting sex-specific effect was seen in mice null for both the $\alpha_{1 \mathrm{~A}}$ and $\alpha_{1 \mathrm{~B}}$-adrenergic receptors.

\section{Phytoestrogens and heart disease}

Another recently emerging issue that needs to be considered in evaluating rodent studies of the cardiovascular system is that standard rodent chow is made of soy and therefore has extremely high levels of the potent phytoestrogens genistein and daidzein (see refs. 36-38). Phytoestrogen concentrations in serum from rodents fed a soy-based diet can be exceedingly high (30,000- to 60,000-fold higher than endogenous estrogen) (36). These phytoestrogens can bind to the estrogen receptor and have potent effects (39). For example, genistein has a tenfold higher affinity for $\operatorname{ER} \beta$ and can transcriptionally stimulate estrogen responsive genes $(40,41)$. For example, male mice fed genistein have a higher degree of DNA methylation than control mice (39). Genistein and other phytoestrogens have been shown to exert potent physiologic effects $(39,42)$. Genistein, in fact, is routinely used in the laboratory setting to inhibit tyrosine kinase receptors and has been shown to inhibit activation of Akt (43). This latter property could be very important in the setting of the heart since Akt activation has been shown to cause significant cardiac hypertrophy (44). Soy-based diets can have an antihypertensive effect on spontaneously hypertensive rats (45). Male rats on a casein versus soy diet have been shown to exhibit less exercise-induced MyHC degradation in skeletal muscle (46). Diets containing phytoestrogen also appear to play a cardioprotective role in ischemia- reperfusion injury in female rats (47). Many human food sources such as soy and soy products have a high phytoestrogen content, so there may also be relevance to the human condition. Soy milk can lower blood pressure in men and women (48) and soy protein supplementation can reduce hypertension in perimenopausal women (49). The Food and Drug Administration recently approved the claim that foods with more than 6.25 grams of soy protein per serving can reduce the risk of heart disease because of its hypocholesterolemic effect (50). How does a diet with supraphysiologic levels of phytoestrogens impact the cardiovascular phenotypes reported in rats and mice? Since most people in the world have diets that do not have this characteristic, are we really able to extrapolate rodent findings in humans? It seems clear that this is an area of research that needs to be pursued.

\section{Conclusions}

Being male or female is a variable that should be dealt with in both basic science and clinical research. It is clear that the response of humans and animals to various disease states can be profoundly affected by the sex of the individual. Further, it is important to recognize that these differences are unlikely to be due solely to sex hormones. For example, some genes on the $\mathrm{X}$ chromosome are expressed at higher levels in females than in males, despite the process of $X$ chromosome inactivation. Additionally, males express genes on the $\mathrm{Y}$ chromosome, which are clearly not present in females. Given the different outcomes exhibited by males and females in disease, it should be possible to determine which pathways contribute to these differences. There are now many candidate pathways to probe such as calmodulin-dependent protein kinase, Akt, glycogen synthase kinase $3 \beta$, and myocyte enhancer factor 2 signaling. The other major issue that needs to be addressed is the evaluation of

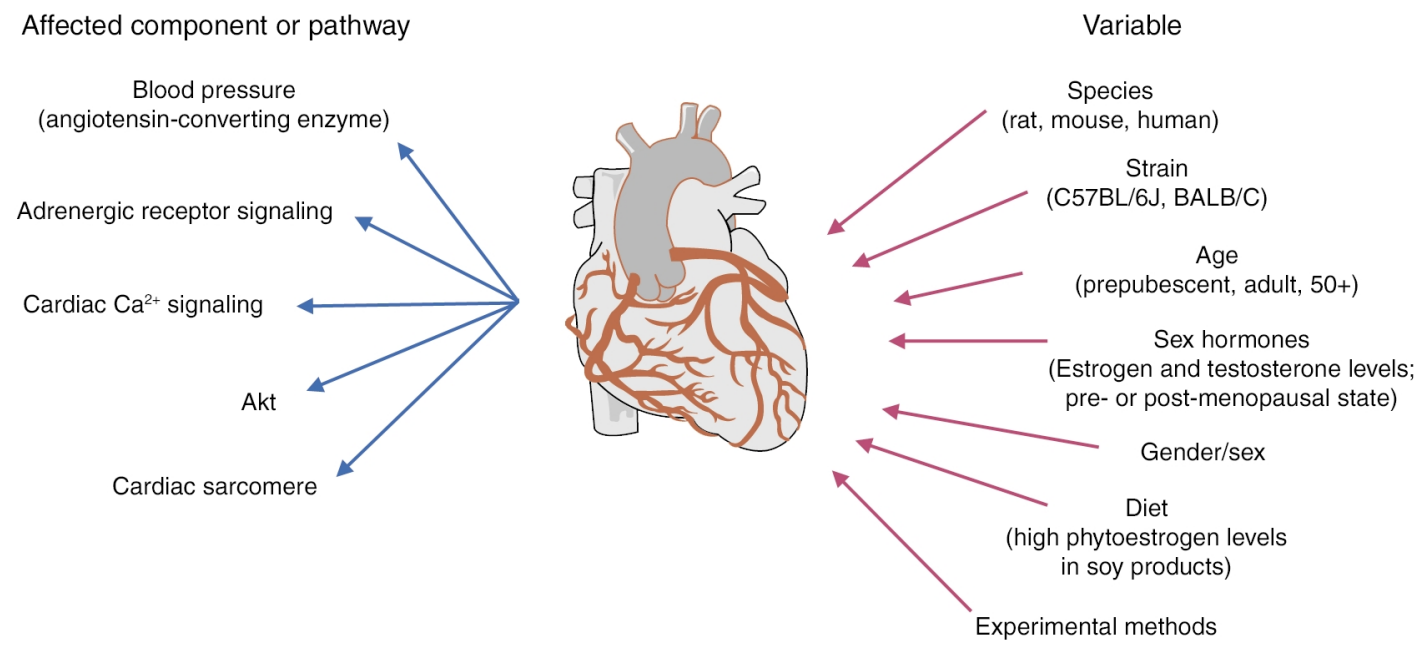

\section{Figure 1}

Pathways and factors affecting the cardiovascular system. The figure indicates how numerous variables, along with factors known to be important in the cardiovascular system, can converge. 
the results of studies conducted on animals fed a soy diet. I predict that diet will be a strong confounding factor in many of these studies and have an effect on sexually dimorphic cardiovascular phenotypes.

1. Committee on Understanding the Biology of Sex and Gender Differences. 2001. Exploring the biological contributions to buman bealth: does sex matter? The National Academies Press. Washington, D.C., USA. 288 pP.

2. Rossouw, J.E., et al. 2002. Risks and benefits of estrogen plus progestin in healthy postmenopausal women: principal results from the Women's Health Initiative randomized control trial. JAMA 288:321-333.

3. O'Connell, T.D., et al. 2003. The $\alpha_{1 \mathrm{~A} / \mathrm{C}^{-}}$and $\alpha_{1 \mathrm{~B}}$-adrenergic receptors are required for physiological cardiac hypertrophy in the doubleknockout mouse. J. Clin. Invest. 111:1783-1791. doi:10.1172/ JCI200316100.

4. Malcolm, D.D., Burns, T.L., Mahoney, L.T., and Lauer, R.M. 1993. Factors affecting left ventricular mass in childhood: the Muscatine Study. Pediatrics. 92:703-709.

5. de Simone, G., et al. 1995. Gender differences in left ventricular growth. Hypertension. 26:979-983.

6. Grandi, A.M., et al. 1992. Influence of age and sex on left ventricular anatomy and function in normals. Cardiology. 81:8-13.

7. Aronow, W.S., Ahn, C., and Kronzon, I. 1999. Comparison of incidences of congestive heart failure in older African-Americans, Hispanics, and whites. Am. J. Cardiol. 84:611-612.

8. De Maria, R., et al. 1993. Comparison of clinical findings in idiopathic dilated cardiomyopathy in women versus men. The Italian Multicenter Cardiomyopathy Study Group (SPIC). Am. J. Cardiol. 72:580-585.

9. Adams, K.F., Jr., et al. 1999. Gender differences in survival in advanced heart failure. Insights from the FIRST study. Circulation. 99:1816-1821.

10. Douglas, P.S., et al. 1995. Gender differences in left ventricle geometry and function in patients undergoing balloon dilatation of the aortic valve for isolated aortic stenosis. NHLBI Balloon Valvuloplasty Registry. Br. Heart J. 73:548-554.

11. Aurigemma, G.P., Silver, K.H., McLaughlin, M., Mauser, J., and Gaasch, W.H. 1994. Impact of chamber geometry and gender on left ventricular systolic function in patients $>60$ years of age with aortic stenosis. Am. J. Cardiol. 74:794-798.

12. Aurigemma, G.P., and Gaasch, W.H. 1995. Gender differences in older patients with pressure-overload hypertrophy of the left ventricle. Cardiology. 86:310-317.

13. Kimmelstiel, C.D., and Konstam, M.A. 1995. Heart failure in women. Cardiology. 86:304-309.

14. Legget, M.E., et al. 1996. Gender differences in left ventricular function at rest and with exercise in asymptomatic aortic stenosis. Am. Heart J. 131:94-100.

15. Grady, D., et al. 2000. Postmenopausal hormone therapy increases risk for venous thromboembolic disease. The Heart and Estrogen/Progestin Replacement Study. Ann. Intern. Med. 132:689-696.

16. Mohan, S.B., Parker, M., Wehbi, M., and Douglass, P. 2002. Idiopathic dilated cardiomyopathy: a common but mystifying cause of heart failure. Cleve. Clin. J. Med. 69:481-487.

17. Fernandez-Sola, J., and Nicolas-Arfelis, J.M. 2002. Gender differences in alcoholic cardiomyopathy. J. Gend. Specif. Med. 5:41-47.

18. National Center for Health Statistics. 1997. Statistical abstract of the United States. 117th edition. US Bureau of the Census. Washington, DC, USA. 83 pp. http://www.census.gov/prod/www/statisticalabstract-us.html.

19. Capasso, J.M., Remily, R.M., Smith, R.H., and Sonnenblick, E.H. 1983. Sex differences in myocardial contractility in the rat. Basic Res. Cardiol. 78:156-171.

20. Schaible, T.F., and Scheuer, J. 1984. Comparison of heart function in male and female rats. Basic Res. Cardiol. 79:402-412.

21. Leblanc, N., Chartier, D., Gosselin, H., and Rouleau, J.L. 1998. Age and gender differences in excitation-contraction coupling of the rat ventricle. J. Physiol. 511:533-548.

22. Freeman, K., et al. 2001. Alterations in cardiac adrenergic signaling and calcium cycling differentially affect the progression of cardiomyopathy. J. Clin. Invest. 107:967-974.

23. Pelzer, T., Shamim, A., Wolfges, S., Schumann, M., and Neyses, L. 1997. Modulation of cardiac hypertrophy by estrogens. Adv. Exp. Med. Biol. 432:83-89.

24. Grohe, C., et al. 1994. Functional estrogen receptors in myocardial and myogenic cells. Circulation. 90:I538. (Abstr.)

25. Grohe, C., et al. 1996. Modulation of hypertensive heart disease by estrogen. Steroids. 61:201-204.

26. Klein-Hitpass, L., Schorpp, M., Wagner, U., and Ryffel, G.U. 1986. An estrogen-responsive element derived from the $5^{\prime}$ flanking region of the
Xenopus vitellogenin A2 gene functions in transfected human cells. Cell. 46:1053-1061.

27. Grohe, C., et al. 1997. Cardiac myocytes and fibroblasts contain functional estrogen receptors. FEBS Lett. 416:107-112.

28. Marsh, J.D., et al. 1998. Androgen receptors mediate hypertrophy in cardiac myocytes. Circulation. 98:256-261.

29. Koenig, H., Goldstone, A., and Lu, C.Y. 1982. Testosterone-mediated sexual dimorphism of the rodent heart. Ventricular lysosomes, mitochondria, and cell growth are modulated by androgens. Circ. Res. 50:782-787.

30. Morano, I., et al. 1990. Regulation of myosin heavy chain expression in the hearts of hypertensive rats by testosterone. Circ. Res. 66:1585-1590.

31. Malhotra, A., Buttrick, P., and Scheuer, J. 1990. Effects of sex hormones on development of physiological and pathological cardiac hypertrophy in male and female rats. Am. J. Physiol. 259:H866-H871.

32. Morris, G.S., et al. 1998. Ovariectomy fails to modify the cardiac myosin isoenzyme profile of adult rats. Horm. Metab. Res. 30:84-87.

33. Scheuer, J., Malhotra, A., Schaible, T.F., and Capasso, J. 1987. Effects of gonadectomy and hormonal replacement on rat hearts. Circ. Res. 61:12-19.

34. Schaible, T.F., Malhotra, A., Ciambrone, G., and Scheuer, J. 1984. The effects of gonadectomy on left ventricular function and cardiac contractile proteins in male and female rats. Circ. Res. 54:38-49.

35. Sharkey, L.C., et al. 1998. Effect of ovariectomy in heart failure-prone SHHF/Mcc-facp rats. Am. J. Physiol. 275:R1968-R1976.

36. Thigpen, J.E., et al. 1999. Phytoestrogen content of purified, open- and closed-formula laboratory animal diets. Lab Anim. Sci. 49:530-536.

37. Degen, G.H., Janning, P., Diel, P., and Bolt, H.M. 2002. Estrogenic isoflavones in rodent diets. Toxicol. Lett. 128:145-157.

38. Boettger-Tong, H., et al. 1998. A case of a laboratory animal feed with high estrogenic activity and its impact on in vivo responses to exogenously administered estrogens. Environ. Health Perspect. 106:369-373.

39. Day, J.K., et al. 2002. Genistein alters methylation patterns in mice. J. Nutr. 132:2419S-2423S.

40. Barkhem, T., et al. 1998. Differential response of estrogen receptor alpha and estrogen receptor beta to partial estrogen agonists/antagonists. Mol. Pharmacol. 54:105-112.

41. Kuiper, G.G., et al. 1998. Interaction of estrogenic chemicals and phytoestrogens with estrogen receptor beta. Endocrinology. 139:4252-4263.

42. Chinni, S.R., Alhasan, S.A., Multani, A.S., Pathak, S., and Sarkar, F.H. 2003. Pleotropic effects of genistein on MCF-7 breast cancer cells. Int. J. Mol. Med. 12:29-34.

43. Matsui, T., et al. 2002. Phenotypic spectrum caused by transgenic overexpression of activated Akt in the heart. J. Biol. Chem. 277:22896-22901.

44. Shioi, T., et al. 2002. Akt/protein kinase B promotes organ growth in transgenic mice. Mol. Cell Biol. 22:2799-2809.

45. Martin, D.S., Breitkopf, N.P., Eyster, K.M., and Williams, J.L. 2001. Dietary soy exerts an antihypertensive effect in spontaneously hypertensive female rats. Am. J. Physiol. Regul. Integr. Comp. Physiol. 281:R553-R560.

46. Nikawa, T., et al. 2002. Effects of a soy protein diet on exercise-induced muscle protein catabolism in rats. Nutrition. 18:490-495.

47. Zhai, P., et al. 2001. Effects of dietary phytoestrogen on global myocardial ischemia-reperfusion injury in isolated female rat hearts. Am. J. Physiol. Heart Circ. Physiol. 281:H1223-H1232.

48. Rivas, M., et al. 2002. Soy milk lowers blood pressure in men and women with mild to moderate essential hypertension. J. Nutr. 132:1900-1902.

49. Washburn, S., Burke, G.L., Morgan, T., and Anthony, M. 1999. Effect of soy protein supplementation on serum lipoproteins, blood pressure, and menopausal symptoms in perimenopausal women. Menopause. 6:7-13.

50. Food and Drug Administration Talk Paper. October 20, 1999. http://www.fda.gov/bbs/topics/answers/ans00980.html.

51. Weinberg, E.O., et al. 1999. Gender differences in molecular remodeling in pressure overload hypertrophy. J. Am. Coll. Cardiol. 34:264-273.

52. Tamura, T., Said, S., and Gerdes, A.M. 1999. Gender-related differences in myocyte remodeling in progression to heart failure. Hypertension. 33:676-680.

53. Wallen, W.J., Cserti, C., Belanger, M.P., and Wittnich, C. 2000. Genderdifferences in myocardial adaptation to afterload in normotensive and hypertensive rats. Hypertension. 36:774-779.

54. Freshour, J.R., Chase, S.E., and Vikstrom, K.L. 2002. Gender differences in cardiac ACE expression are normalized in androgen-deprived male mice. Am. J. Physiol. Heart Circ. Physiol. 283:H1997-H2003.

55. Miyata, S., Minobe, W., Bristow, M.R., and Leinwand, L.A. 2000. Myosin heavy chain isoform expression in the failing and nonfailing human heart. Circ. Res. 86:386-390.

56. Trepanier-Boulay, V., St-Michel, C., Tremblay, A., and Fiset, C. 2001. Gender-based differences in cardiac repolarization in mouse ventricle. Circ. Res. 89:437-444.

57. Wu, Y., and Anderson, M.E. 2002. Reduced repolarization reserve in 
ventricular myocytes from female mice. Cardiovasc. Res. 53:763-769.

58. Freeman, K., et al. 2001. Progression from hypertrophic to dilated cardiomyopathy in mice that express a mutant myosin transgene. Am. J. Physiol. Heart Circ. Physiol. 280:151-159.

59. Tardiff, J.C., et al. 1999. Cardiac troponin T mutations result in allelespecific phenotypes in a mouse model for hypertrophic cardiomyopathy. J. Clin. Invest. 104:469-481.

60. Haghighi, K., et al. 2001. Superinhibition of sarcoplasmic reticulum function by phospholamban induces cardiac contractile failure. J. Biol. Chem. 276:24145-24152.

61. Dash, R., et al. 2003. Differential regulation of p38 mitogen-activated protein kinase mediates gender-dependent catecholamine-induced hypertrophy. Cardiovasc. Res. 57:704-714.

62. Duan, J., et al. 2003. Influence of gender on ethanol-induced ventricular myocyte contractile depression in transgenic mice with cardiac overexpression of alcohol dehydrogenase. Comp. Biochem. Physiol. Mol. Integr. Physiol. 134:607-614.

63. Janczewski, A.M., et al. 2003. Morphological and functional changes in cardiac myocytes isolated from mice overexpressing TNF- $\alpha$. Am.J. Physiol. Heart Circ. Physiol. 284:H960-H969.

64. Nohammer, C., et al. 2003. Myocardial dysfunction and male mortality in peroxisome proliferator-activated receptor alpha knockout mice overexpressing lipoprotein lipase in muscle. Lab Invest. 83:259-269.

65. Du, X.J., et al. 2003. Increased myocardial collagen and ventricular diastolic dysfunction in relaxin deficient mice: a gender-specific phenotype. Cardiovasc. Res. 57:395-404.

66. Cross, H.R., Murphy, E., Koch, W.J., and Steenbergen, C. 2002. Male and female mice overexpressing the beta(2)-adrenergic receptor exhibit differences in ischemia/reperfusion injury: role of nitric oxide. Cardiovasc. Res. 53:662-671. 